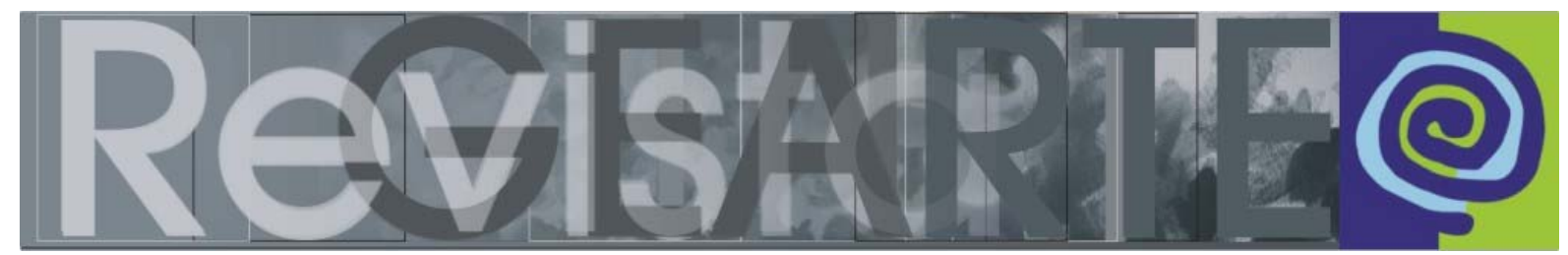

ISSN 2357-9854

\title{
Alfabetização audiovisual e pedagogia das imagens
}

\author{
Juliana Costa (UFRGS - Brasil) \\ Maria Carmen Silveira Barbosa (UFRGS - Brasil)
}

\begin{abstract}
RESUMO
O artigo apresenta um trabalho desenvolvido na disciplina de Arte do ensino fundamental de uma escola pública no Município de Porto Alegre permeado pelas ações do Programa de Alfabetização Audiovisual, fazendo uma reflexão acerca da alfabetização audiovisual a partir da possibilidade de uma pedagogia das imagens. A pergunta investigativa que o direciona buscou conhecer de que forma os estudantes se apropriaram dos modos de fazer do cinema por meio da fruição dos trechos postos em relação, estabelecendo assim um diálogo entre as imagens em movimento observadas na tela e as imagens filmadas por eles nos processos de produção. Discorreremos também sobre a possibilidade de uma alfabetização audiovisual através de uma pedagogia das imagens, partindo da premissa de perguntar e responder com imagens.
\end{abstract}

PALAVRAS-CHAVE

Alfabetização Audiovisual. Pedagogia das Imagens. Cinema e Educação.

\section{ABSTRACT}

This paper presents a work in art discipline, in a class of elementary school at a public school in Porto Alegre City, permeated by the actions of Programa de Alfabetização Audiovisual, discussing about audiovisual literacy as of the possibility of teaching images. The investigative question that directs this paper is how students have appropriated the ways of making cinema through the fruition of excerpts brought into relation, thus establishing a dialogue between the moving images seen on the screen and the images shot by them in production processes. We will discuss also about the possibility of visual literacy through a pedagogy of the images, based on the premise of asking and answering with images.

\section{KEYWORDS}

Audio visual literacy. Pedagogy of images. Cinema and education.

Desde o ano de 2008 a Universidade Federal do Rio Grande do Sul e as Secretarias de Cultura e de Educação do Município de Porto Alegre realizam o Programa de Alfabetização Audiovisual (PPA), que tem como objetivo promover diferentes ações que aproximem o audiovisual da escola pública e refletir sobre a intersecção entre audiovisual e educação. As ações do PAA oferecem suporte para a constituição de um contexto educacional interessante para que diferentes escolas e professores criem percursos de trabalho autônomos, mas que, em função desse Programa em comum, possam estabelecer interlocuções tanto no sentido da formação dos profissionais tanto da possibilidade de os alunos participarem dos eventos propostos e estabelecerem contatos e conexões com 
experiências de outras crianças, jovens e adultos de distintas escolas. 0 Programa de Alfabetização Audiovisual promove ações voltadas diretamente tanto aos estudantes, Festival Escolar de Cinema, Mostra Olhares da Escola e Oficinas de Introdução à Realização Audiovisual; como aos professores, workshops, seminários e mais recentemente o projeto Vagalume - Laboratório de Estudos em Audiovisual e Educação, um laboratório que visa à investigação de práticas que envolvem o audiovisual em contexto educativo. O PAA atua também na reflexão acerca de suas práticas, e entre os diversos textos publicados por membros da sua extensa equipe, destacamos o livro Escritos de Alfabetização Audiovisual. A publicação, lançada durante o II Seminário Internacional de Cinema e Educação, promovido pelo Programa em 2014 na cidade de Porto Alegre, contou com reflexões de diversos autores ligados às áreas de cinema e educação e teve a organização de Maria Carmen Silveira Barbosa e Maria Angélica dos Santos, coordenadoras do Programa de Alfabetização Audiovisual (BARBOSA; SANTOS, 2014).

Neste artigo vamos apresentar um trabalho desenvolvido na disciplina de Arte do currículo formal de uma turma de $8^{\circ}$ ano do ensino fundamental de uma escola da rede estadual localizada em bairro de classe média da cidade de Porto Alegre $^{1}$. O grupo consistia em 18 alunos, sendo apenas quatro meninas, e os encontros, de 50 minutos cada, aconteceram duas vezes por semana durante dois meses. Permearam este trabalho três ações do Programa de Alfabetização Audiovisual: o $6^{\circ}$ Festival Escolar de Cinema, a Oficina de Introdução à Realização Audiovisual e a IV Mostra Olhares da Escola.

A pergunta investigativa que direciona este artigo buscou conhecer de que forma os estudantes se apropriaram dos modos de fazer do cinema por meio da fruição dos trechos postos em relação, estabelecendo assim um diálogo entre as imagens em movimento observadas na tela e as imagens filmadas por eles nos processos de produção. Discorreremos também sobre a possibilidade de uma

1 Tomamos para análise uma experiência do trabalho com o cinema em sala da aula, realizado pela então aluna de graduação Juliana Costa, em seu estágio curricular obrigatório para a conclusão do Curso de Licenciatura em Artes Visuais na Universidade Federal do Rio Grande do Sul. 
alfabetização audiovisual através de uma pedagogia das imagens, partindo da premissa de perguntar e responder com imagens.

\title{
O cinema na sala de aula: produzir repertório, experiência de sensibilidade e pensamento visual
}

Para Jaques Aumont (2008, p. 23), “o cinema não é uma língua, mas serve para pensar. Ou é um modo de pensar." Anita Leandro (2001, p. 31), no artigo Da imagem pedagógica à pedagogia da imagem, complementa:

\begin{abstract}
O trabalho do filme, o filme como local de trabalho, local de realização do ato criador do homem e, portanto, de transformação do mundo: essa parece ser a pedagogia essencial da imagem. A imagem pensa e faz pensar, e é nesse sentido que ela contém uma pedagogia intrínseca.
\end{abstract}

No que consistiria então uma pedagogia das imagens ou uma pedagogia pelas imagens? Como trabalhar com o cinema em sala de aula para fazer pensar o próprio cinema?

Apesar de esta reflexão ser norteada pelo conceito de alfabetização audiovisual, precisamos destacar a escolha de se trabalhar com o cinema e suas especificidades em sala de aula. Não pretendemos nos estender sobre as diferenças conceituais e estruturais entre cinema e vídeo, que acreditamos serem cada vez menores, se é que ainda existem. Recortamos cinema dentro de duas perspectivas: a primeira, de produções inseridas dentro de uma história do cinema e a segunda, a de produções criadas para serem exibidas no contexto da sala escura. A primeira se justifica pela crença na importância de se criar, a partir da educação, uma cultura cinematográfica, voltada para o campo das artes. A segunda diz respeito à crença no contato efetivo com a obra de arte por meio da experiência estética, facilitado especialmente no cinema pelo seu dispositivo de exibição.

O pressuposto que levantamos para o trabalho com o cinema na educação não parte de se estabelecer uma "gramática" para assistir aos filmes, analisando os códigos contidos em suas imagens e narrativas, mas sim de propor um trabalho de experiência do olhar. Inês Teixeira, Jorge Larrosa e José 
de Souza Miguel Lopes (2014, p.11) em A infância vai ao cinema, abordam a insuficiência da linguagem verbal para o trabalho com as imagens:

\begin{abstract}
Falar ou escrever sobre cinema é muito difícil. Coloca-se, obviamente, um problema de tradução. Como traduzir com palavras o que não é feito de palavras? [...] É bem possível que ali onde não se pode dizer nada, comece o cinema; justamente ali. É bem possível que o cinema, ou dito de outro modo, a dimensão propriamente cinematográfica do cinema, o que faz com que o cinema seja cinema e não outra coisa esteja justamente naquilo que só se pode dizer com o cinema, que não se pode dizer de outra maneira, com outros meios ou com outras linguagens.
\end{abstract}

Para Deleuze ${ }^{2}$, é possível mostrar que o cinema pensa através de seus realizadores. Nessa perspectiva, alguns autores efetivamente desenvolveram uma teoria a respeito do próprio cinema no interior de suas obras, dialogando a respeito da história das formas no fazer cinematográfico. Falamos assim em uma história das formas cinematográficas. Trata-se de uma epistemologia estética do cinema. De acordo com Luiz Carlos de Oliveira Jr. são "imagens que se apresentam como 'formas pensantes', respostas dadas através de signos icônicos a problemas que são da ordem não só do dramatúrgico-ficcional como também teórico-conceitual" (2015, p. 3).

Ao tomar a mise en scène ${ }^{3}$ como um ato de reflexão teórica, o que uniria os filmes e forjaria uma continuidade, interessa menos a sucessão cronológica do que o trajeto visual que as imagens formam quando convidadas a dialogar entre elas. Assim a ampliação de repertório do estudante permite a construção de um processo inconsciente de memória artística das formas (OLIVEIRA JR., 2015), o tornando apto a, a partir daí, construir narrativas próprias para a fruição e produção de peças audiovisuais, que, de certa forma, também dialoguem com

2 A explanação a sobre os conceitos deleuzianos a respeito do cinema neste artigo refere-se ao texto de Jorge Vasconcellos "A pedagogia da imagem: Deleuze, Godard - ou como produzir um pensamento do cinema" (2008).

3 Trataremos do complexo conceito de mise en scène de uma forma sintética para fins de reflexão neste artigo como "um pensamento em ação, a encarnação de uma ideia, a organização e a disposição de um mundo para o espectador. Acima de tudo trata-se de uma arte de colocar os corpos em relação no espaço e de evidenciar a presença do homem no mundo ao registrá-lo em meio às ações, cenários e objetos que dão consistência e sensação de realidade à sua vida." (OLIVEIRA JR, 2013, p. 8). 
essa história/memória, colocando o espectador em condições de construir, ele mesmo, um saber sobre o cinema.

Pelo seu poder de estabelecer relações de afeto, as imagens do cinema integram-se ao escopo do imaginário do espectador, passando a constituir matéria de memória, aprofundando o que entendemos por repertório. André Malraux conceituou este arcabouço de memória das imagens como um museu imaginário, um "lugar mental" sem fronteiras que nos habita. Esse lugar mental abole as fronteiras de hierarquia, de tempo e de espaço entre as imagens que nos constituem. Esse local imaginário seria ainda, para Malraux, a fonte da criação artística, que insere o sujeito em uma narrativa da história das formas, sendo o artista mais influenciado pelo encontro com as obras de arte do que por aquilo que representam:

(...) toda narrativa está mais próxima das narrativas anteriores que do mundo que as cerca, e as obras mais divergentes, quando reunidas no museu ou na biblioteca, não se acham juntas pela relação que mantêm com a realidade, mas com a relação que têm entre si (MALRAUX apud SILVA, 2002, p.159).

Para Marcos Villela Pereira, as diversas formas de racionalidade só podem ser experimentadas quando se possui uma competência para fruir o objeto ou acontecimento artístico e, ainda, que esta formação passa pela ampliação da capacidade perceptiva através da ampliação do repertório do sujeito receptor: "Ampliar o repertório cultural, ampliar o repertório de experiências representa, assim uma ampliação da capacidade dos sujeitos orientarem sua percepção e compreensão ante as infinitas possibilidades da existência." (PEREIRA, 2011, p. 119). E ainda:

\footnotetext{
a vida - como a arte -, não se define: a vida - e a arte - é uma coleção de exemplos. Nesse sentido, postulo a ideia da experiência estética como uma oportunidade de ampliação, de desvelamento e de expansão da subjetividade na medida em que representa uma abertura para essa coleção de exemplos (p. 119-120).
}

Longe de se querer criar um repertório alheio ao estudante, que o capacite a ser uma espécie de conhecedor de uma história que não a sua, a ampliação de repertório a partir da perspectiva de história das formas o enreda em uma teia 
de memórias imagéticas, relacionando o seu repertório com o repertório adquirido, que fará parte da sua constituição enquanto sujeito. Para Favaretto:

Tomar o cinema como instância educativa implica redirecionar as
tradicionais questões sobre as relações entre pensamento e
sensibilidade, entre juízos de gosto e prazer da fantasia, entre
experiência reflexiva e consumo de experiências. Tratando-se de
cinema e, mais extensamente, de todas as novas tecnologias das
imagens, pergunta-se se o que estaria em questão na escola não seria
a constituição de verdadeiros laboratórios experimentais da
sensibilidade e do pensamento visual. (apud SILVA et al, 2013, p. 145).

Trata-se, portanto, de pensar um laboratório de experimentações de fruição das imagens em movimento, de proporcionar o encontro com o cinema e sua melhor forma de exibição possível, propiciar o tempo de assistir aos filmes, de olhar as imagens de forma ativa, de olhar novamente, de fazer livres relações destas com repertórios imagéticos diversos. Trata-se de perguntar e de responder com imagem.

\section{Perguntando e respondendo com imagens}

O projeto com os jovens foi realizado em quatro movimentos formativos: ida à sessão do $6^{\circ}$ Festival Escolar de Cinema, experiências com exibição e produção de filmes em sala de aula, realização da Oficina de Introdução à Realização Audiovisual e exibição do filme Música e Preconceito, curtametragem filmado pelos estudantes, em sessão da IV Mostra Olhares da Escola. As experiências de sala de aula foram divididas em três proposições, cada uma consistindo em uma aula de exibição de trechos de filmes postos em relação seguida de uma aula de exercícios de filmagem.

O percurso iniciou com a ida dos estudantes à sessão do filme Hoje EU Quero Voltar Sozinho ${ }^{4}$, de Daniel Ribeiro, dentro da programação voltada à faixa etária de 12 a 14 anos do $6^{\circ}$ Festival Escolar de Cinema. O Festival Escolar de Cinema é a maior ação do Programa de Alfabetização Audiovisual em termos de alcance de público. Até o ano de 2015 foram realizadas sete edições, atingindo mais de 25.000 estudantes e professores das redes públicas de ensino de Porto

4 Hoje Eu Quero Voltar Sozinho, 2013, conta a história de um adolescente cego que tem sua primeira experiência amorosa com um colega de classe. 
Alegre. A programação do Festival é dividida em faixas etárias que vão da educação infantil, passando pelo ensino médio até educação de jovens e adultos (EJA) e objetiva apresentar ao público escolar obras de menor acesso em relação a filmes do circuito comercial, no dispositivo clássico de exibição cinematográfica: a sala escura.

Os debates que se seguiram após a ida ao cinema foram em relação às diferenças da recepção cinematográfica na sala de cinema e em ambiente doméstico e à temática do filme, que tem sua ação transcorrida basicamente em contexto escolar. A discussão introduziu a primeira proposição de trabalho em sala de aula, com exibição e exercícios de filmagem que teve como tema: filmando a sala de aula.

Com o objetivo de expor aos estudantes os mecanismos de obtenção de imagem e colocá-los ao lado do diretor nas escolhas dos modos de fazer cinema, sem necessariamente trabalhar com o vocabulário "gramatical" desta linguagem ${ }^{5}$, a pergunta que guiou o trabalho com os filmes em todos os módulos foi: onde e como está a câmera?

Na proposição 1 foram selecionados trechos de cenas de sala de aula dos seguintes filmes: Os Incompreendidos (1959), de François Truffaut; Onde Fica a Casa do Meu Amigo (1983), de Abbas Kiarostami; A Esquiva (2003), de Abdellatif Kechiche; Os Indigentes do Bom Deus (2000), de Jean Claude Brisseau e Elephant (2003), de Gus Van Sant. Os filmes foram escolhidos pelos critérios de aproximação temática ao universo dos estudantes, diversidade de realidades representadas e diversidade de posicionamento, movimentos de câmera e duração de planos. O exercício prático proposto foi o de filmar a sala de aula em três planos. O equipamento utilizado para todos os exercícios de filmagem na escola foi uma câmera de filmagem Canon semiprofissional e o tempo disponível foi a duração de um período regular, 50 minutos.

5 O único conceito trabalhado durante o projeto foi o de "plano", tanto em relação ao tempo (duração) quanto ao espaço (enquadramento e distância do objeto filmado). 
Neste momento inicial do projeto, logo após assistir aos trechos dos filmes, o diálogo que os estudantes estabeleceram com esses foi basicamente com a temática - normalmente a primeira camada acessada pelo espectador sendo abordados temas sobre a autoridade do professor em sala de aula (Onde Fica a Casa do Meu Amigo) e a transgressão dos estudantes em relação a essa autoridade (Os Incompreendidos e Os Indigentes do Bom Deus).

A proposição 2 tinha como objetivo, não verbalizado para os alunos, a percepção de uma narrativa inerente à imagem em movimento, sem o artifício da montagem, e através da proposta do exercício de filmagem elaborado por Alain Bergala, em A Hipótese Cinema(2007), chamado de Minuto Lumière ${ }^{6}$.

$\mathrm{Na}$ aula de exibição, houve uma breve introdução ao início do cinema, a descrição do dispositivo do cinematógrafo, suas limitações e a revolução tecnológica e perceptiva que provocou na época. Em seguida foram exibidos oito filmes: Chegada de um trem à estação, 1895; Saída da fábrica, 1895; Refeição de um bebê, 1895; Demolição de um muro, 1895; O jardineiro regado, 1895; Jogo de cartas, 1895; Partindo de Jerusalém pela estrada de ferro, 1895 e Engate de um caminhão, 1896.

Apesar de os "Minutos Lumière" dos estudantes terem explorado questões muito interessantes em relação à percepção de movimento, profundidade de campo, informações sonoras do extracampo, o diálogo entre as imagens assistidas e produzidas, que é o objeto de reflexão deste artigo, aconteceu posteriormente, na realização do curta-metragem final, conforme observaremos mais adiante. Também é importante pontuar que, do ponto de vista pedagógico, o objetivo proposto nem sempre é atingido diretamente ou ao menos não no momento que se espera; muitas vezes os resultados podem aparecer mesmo em situações extraescolares, longe das vistas do professor, o que torna a avaliação dos métodos bastante complexa.

6 O Minuto Lumière consiste na filmagem de um plano de 50 segundos, com a câmera parada, sem a utilização de zoom, com temática cotidiana, sem encenação por parte dos atores. 
A proposição 3 apresentou o cinema brasileiro contemporâneo e tinha como objetivo ampliar o repertório dos estudantes nesse campo e trabalhar com travelling7. Foram selecionados trechos de filmes de dois diretores pernambucanos, considerando a importância de produção cinematográfica desse estado dentro do cinema nacional nas últimas duas décadas. Os trechos exibidos foram dos filmes Amarelo Manga e Febre do Rato, de Claudio Assis, 2002 e 2011, respectivamente e O Som ao Redor, de Kleber Mendonça, 2012.

Nesta etapa do trabalho a percepção dos estudantes em relação aos modos do fazer cinematográfico já estava muito mais aguçada em relação ao início do projeto. De imediato foi percebida pelos alunos a semelhança em relação à movimentação da câmera e à duração dos planos. Essa percepção foi o mote para o exercício de filmagem deste módulo, que consistiu na filmagem de um plano longo com a câmera em movimento, acoplada a uma bicicleta ou skate. Pela natureza do exercício, que solicitava uma regra formal mais específica do que os outros, já observamos a assimilação dos procedimentos de filmagem nos vídeos produzidos. O primeiro grupo fez uma referência explícita ao travelling de $\mathrm{O}$ Som ao Redor. O segundo recuperou a câmera circular do filme Elephant, exibido na proposição 1 de sala de aula, invertendo a lógica do posicionamento da câmera - que no filme de Gus Van Sant gira em torno do próprio eixo filmando uma roda de alunos - e no exercício produzido faz um giro de $360^{\circ}$ ao redor de um estudante.

$\mathrm{Na}$ terceira etapa do projeto, foi ministrada uma Oficina de Introdução à Realização Audiovisual, oferecida pelo Programa de Alfabetização Audiovisual, em que a cineasta Laura Mansur ${ }^{8}$ auxiliou os alunos na execução de um curta-

7 Travelling, na terminologia de cinema e audiovisual, é todo movimento de câmera em que esta realmente se desloca no espaço - em oposição aos movimentos de panorâmica, nos quais a câmera apenas gira sobre o seu próprio eixo, sem se deslocar. Fonte: <https://pt.wikipedia.org/wiki/Travelling>. Acesso em 27 de setembro de 2015.

8 Laura Mansur é cineasta, tendo atuado como diretora e assistente de direção em diversos curtas e longas-metragens brasileiros. É também oficineira do Programa de Alfabetização Audiovisual desde 2013. 
metragem. A oficina de 20 horas-aula foi realizada no horário de aula dos estudantes.

A oficina, pelo desafio proposto de produzir um filme curta-metragem com narrativa estabelecida, acabou sendo mais estrutural no trabalho com a linguagem cinematográfica do que as aulas que vínhamos desenvolvendo com o grupo. A metodologia aplicada foi a de seguir os passos básicos da realização cinematográfica, a constar: elaboração de roteiro, decupagem ${ }^{9}$ do roteiro, filmagem e montagem. Poderíamos refletir sobre este rico processo a partir de diversos pontos, mas para a análise que este artigo propõe vamos relacionar diversos planos filmados no curta-metragem Música e Preconceito, realizado pelos estudantes e o repertório adquirido no decorrer do projeto, sob a perspectiva de uma história das formas cinematográficas construída pela apropriação destes modos de fazer cinema.

\section{Música e Preconceito: imagens-resposta}

Ao analisar o filme produzido é possível constatar que diversos planos pensados pelos alunos de alguma forma realizam uma interpretação, ou ainda uma reflexão dos trechos exibidos em sala de aula.

O primeiro plano do filme possui um posicionamento de câmera e um tempo de duração muito similar ao filme $A$ Saída dos Operários da Fábrica, dos Irmãos Lumière (Figura 1). Nele um grupo de estudantes entra no colégio, seguido de longe pelo protagonista. A câmera está parada, em posição frontal, os atores se movimentam em direção a ela e o plano tem quase a mesma duração daquele dos irmãos franceses, cerca de 30 segundos (Figura 2).

9 Em cinema e audiovisual, decupagem é o planejamento da filmagem, a divisão de uma cena em planos e a previsão de como estes planos vão se ligar uns aos outros através de cortes. Fonte: <https://pt.wikipedia.org/wiki/Decupagem>. Acesso em 27 de setembro de 2015. 
Figura 1 - Frame de A Saída dos Operários da Fábrica, Irmãos Lumière, 1895

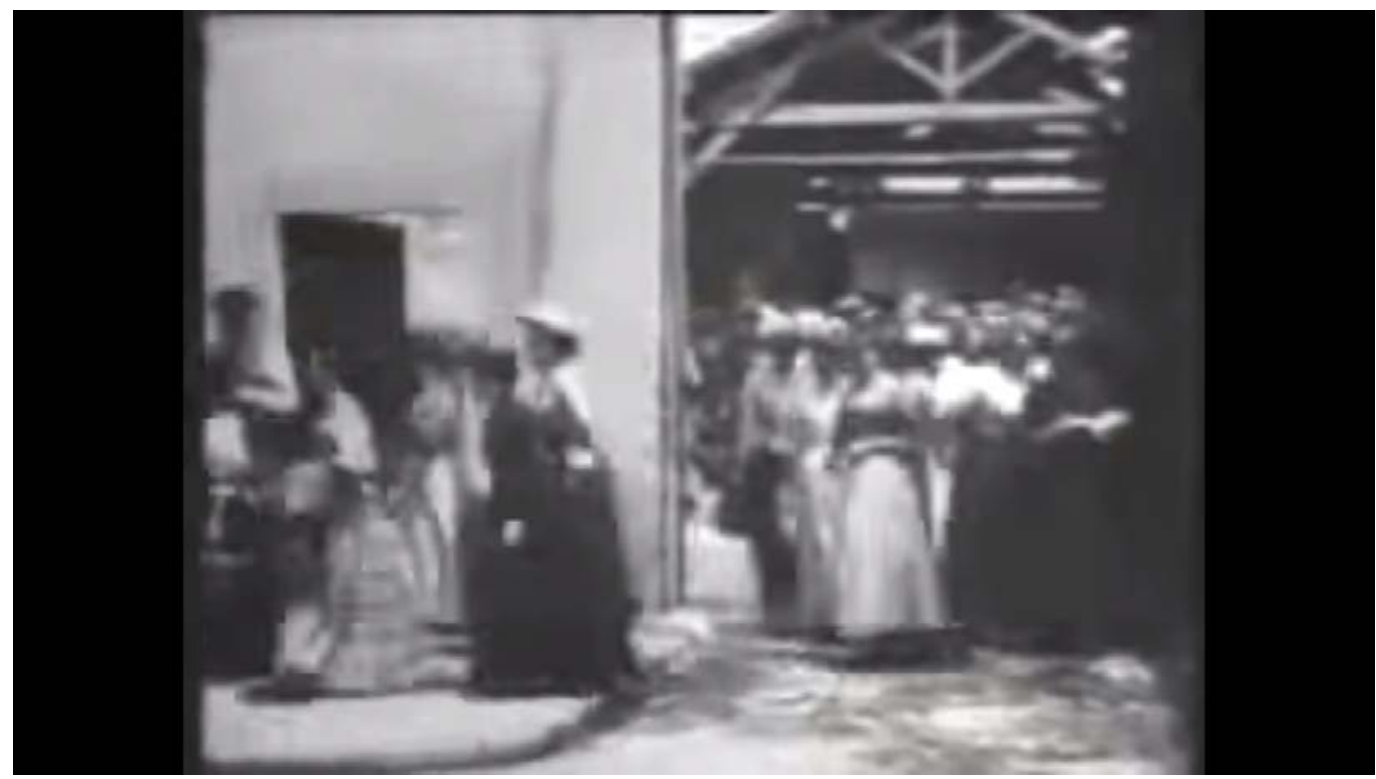

Fonte: Frame extraído do DVD do material didático Inventar com a Diferença.

Figura 2 - Frame de Música e Preconceito, $8^{\circ}$ ano, EEEF Leopolda Barnewitz, 2014

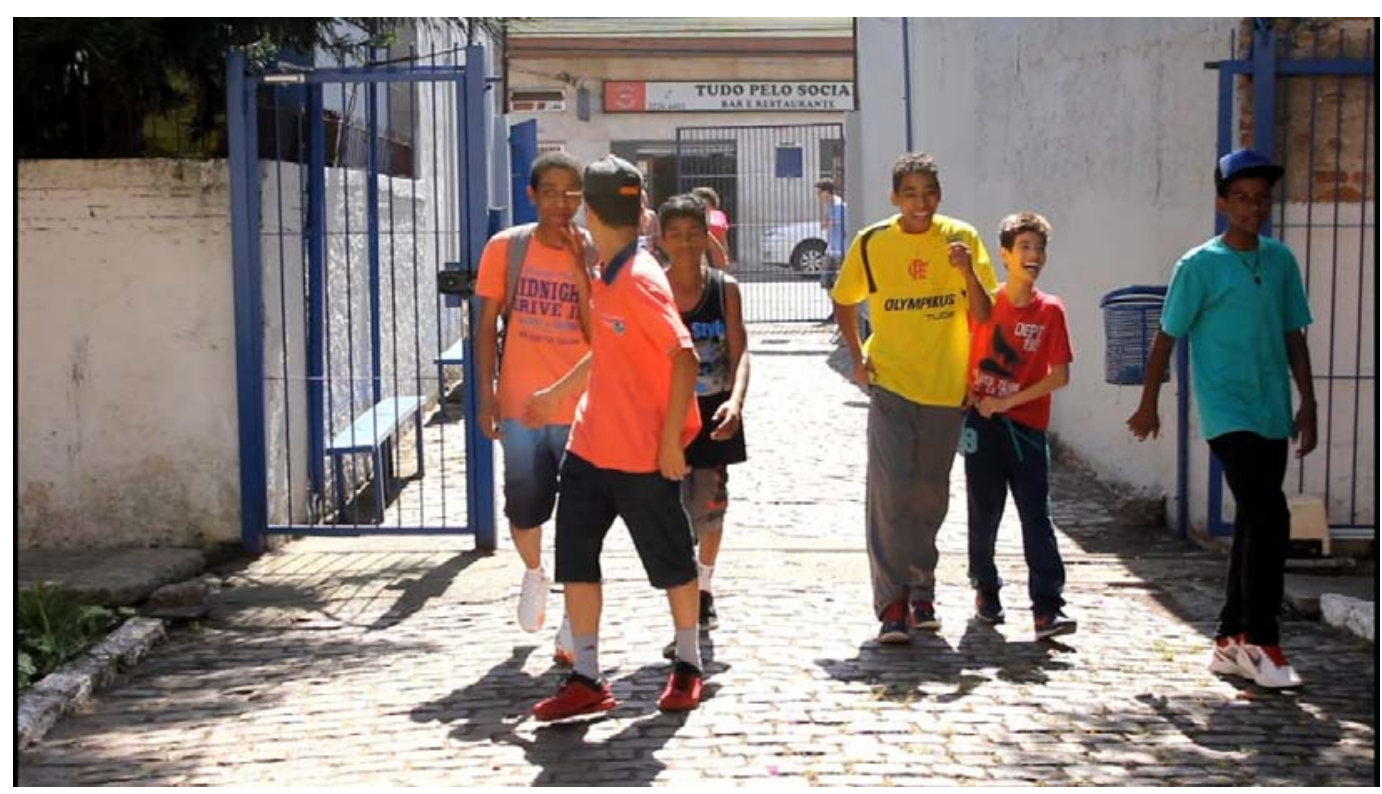

Fonte: Frame extraído do arquivo digital original do filme.

Outra referência observada é a filmagem circular de um grupo - já explorada nos exercícios de filmagem do módulo sobre cinema brasileiro contemporâneo - tomada do centro, com a câmera girando em torno do eixo, percorrendo os rostos dos atores (Figura 4), muito parecida com o trecho do filme Elephant, exibido no módulo da sala de aula (Figura 3). 
Figura 3 - Frame de Elepahnt, Gus Van Sant, 2000

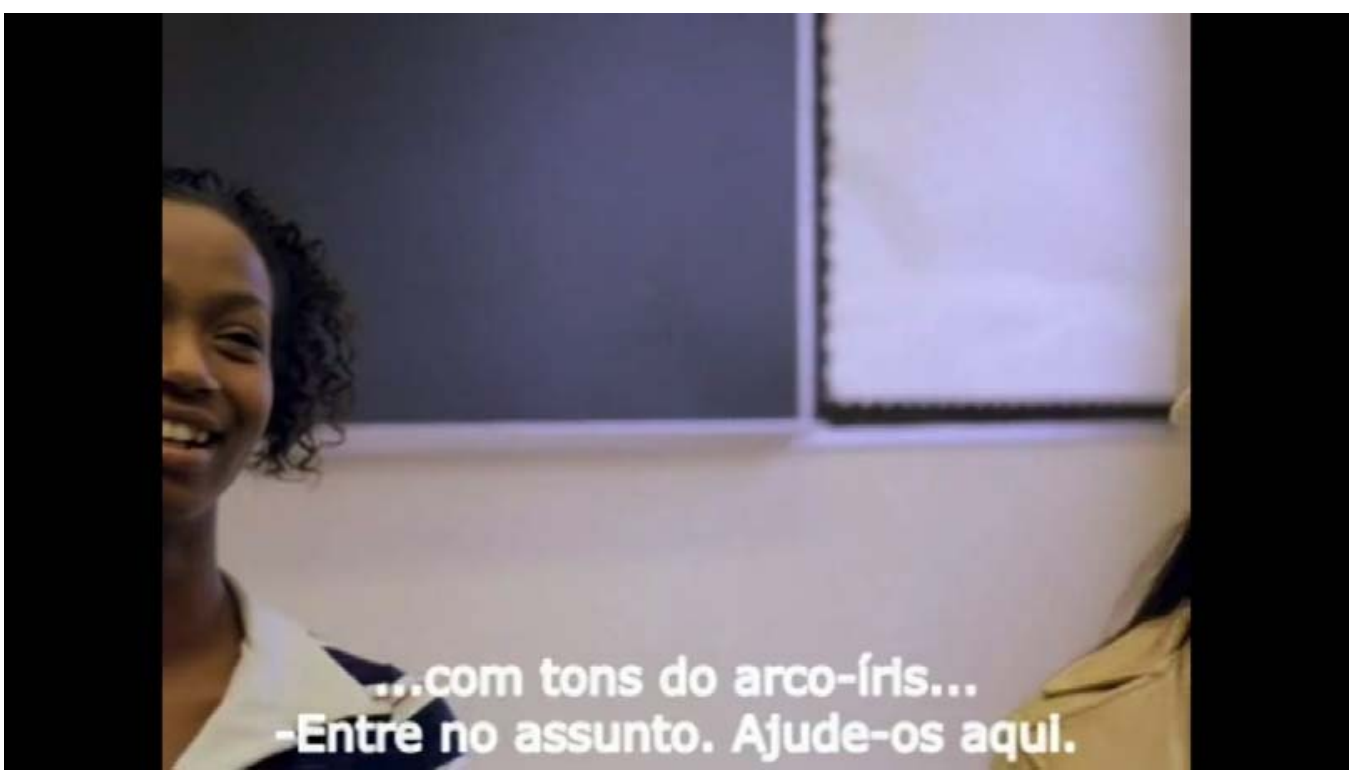

Fonte: Frame extraído de DVD original, acervo pessoal.

Figura 4 - Frame de Música e Preconceito, $8^{\circ}$ ano, EEEF Leopolda Barnewitz, 2014

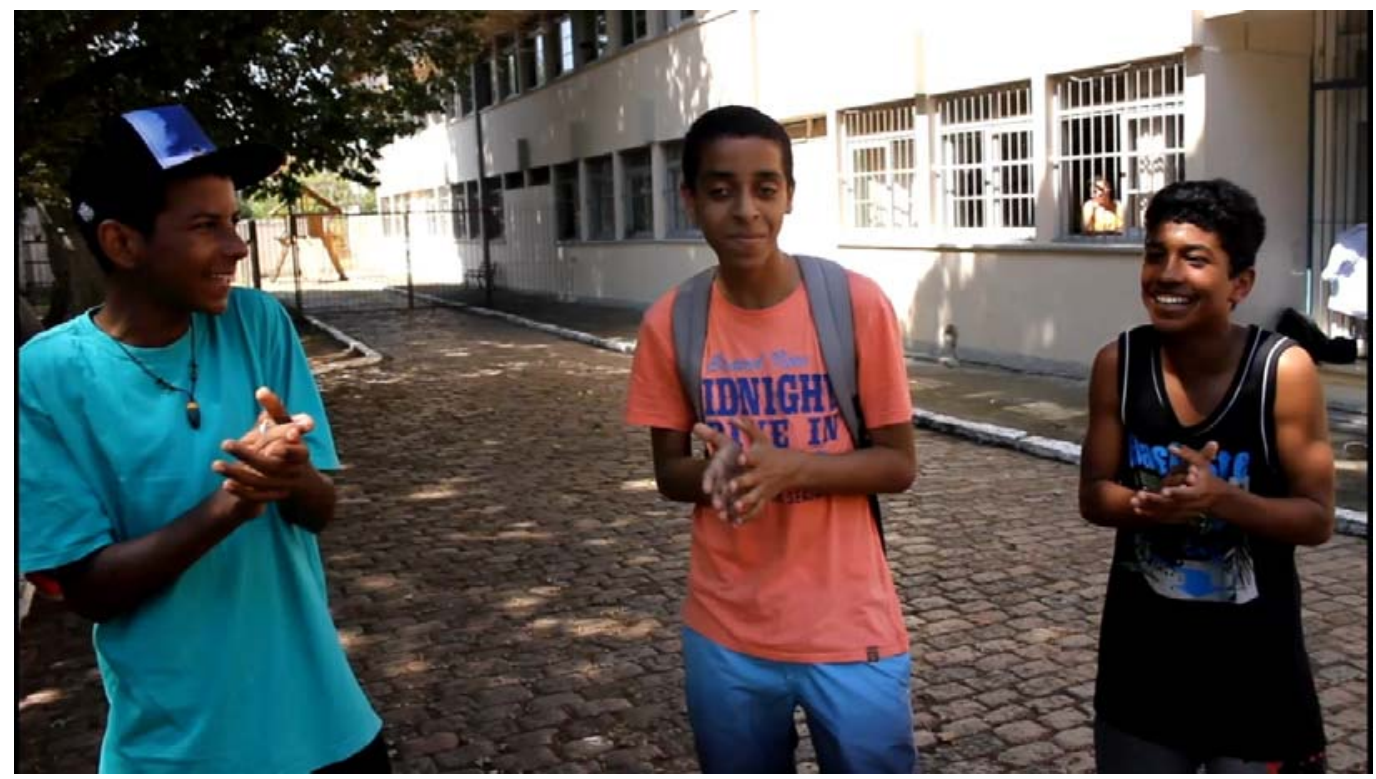

Fonte: Frame extraído do arquivo digital original do filme.

Nas filmagens da cena de sala de aula, observamos duas referências claras à cena do filme Os Incompreendidos, exibida em sala de aula. A primeira é na tomada do protagonista copiando a matéria no caderno (Figura 5). A sutil diferença entre o posicionamento das câmeras - que no filme de Truffaut está às costas do aluno e com uma perspectiva um pouco elevada, ao contrário da dos alunos (Figura 6), que está de frente e mais central - nos mostra a apropriação deste repertório imagético adquirido, que recria da memória de uma imagem, sem trazer à consciência uma mera reprodução formal. 
Figura 5 - Frame de Os Incompreendidos, François Truffaut, 1959

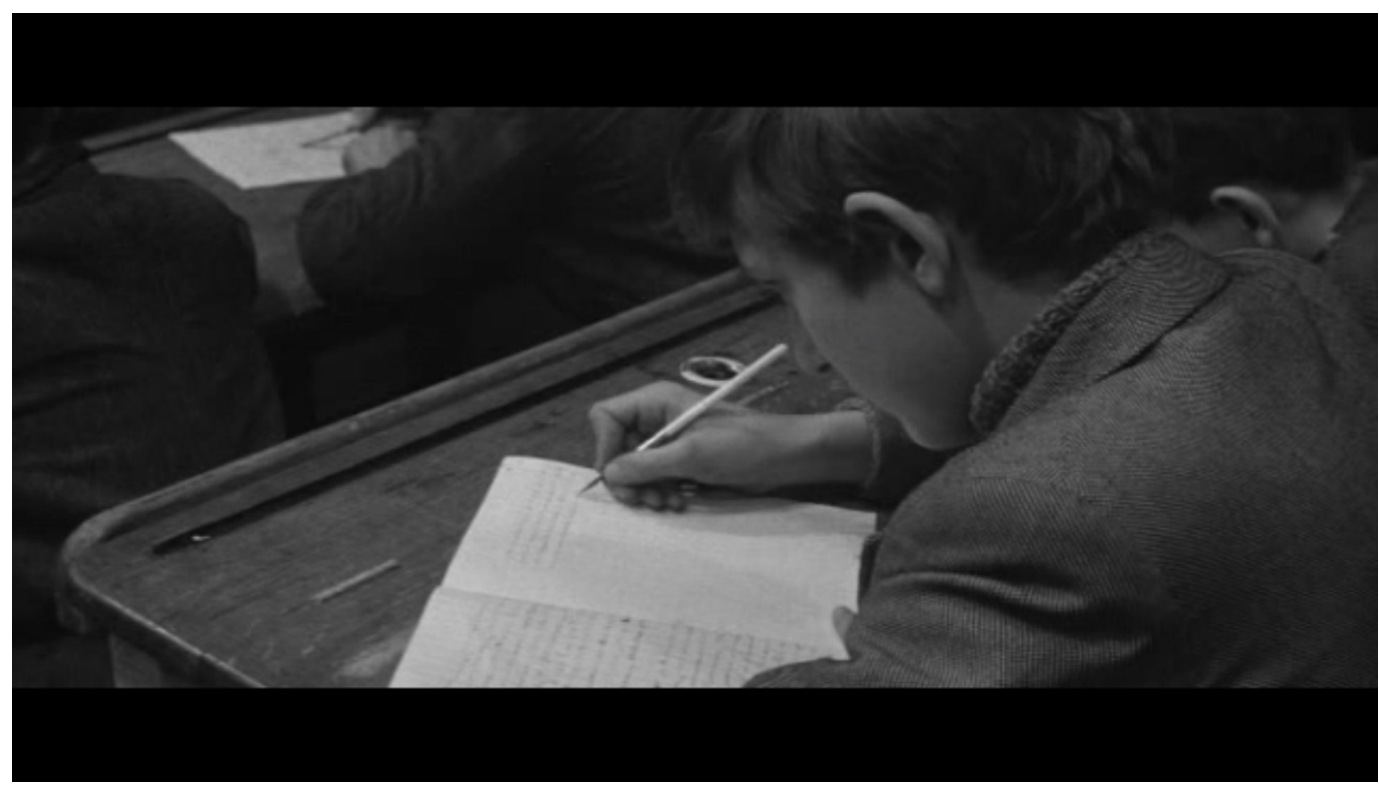

Fonte: Frame extraído de DVD original, acervo pessoal.

Figura 6 - Frame de Música e Preconceito, 8ªno, EEEF Leopolda Barnewitz, 2014

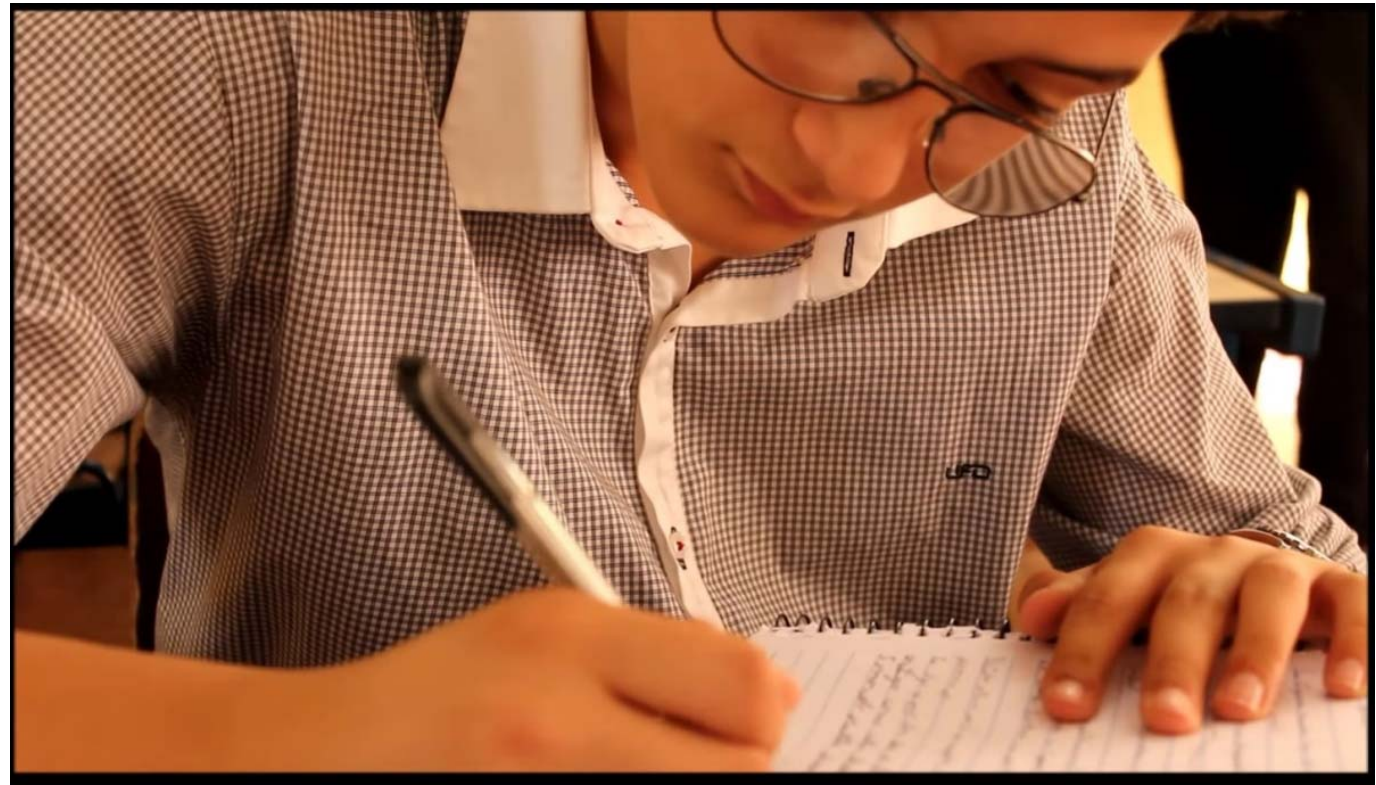

Fonte: Frame extraído do arquivo digital original do filme.

A segunda referência a esse filme é na filmagem frontal da sala de aula e no movimento de câmera que se segue. Em Os Incompreendidos, a câmera faz uma panorâmica ${ }^{10}$ para a esquerda da sala seguindo o professor que se desloca ao fundo (Figura 7). No filme Música e Preconceito, a câmera faz uma

10 Panorâmica, em cinema e audiovisual, é um movimento de câmera em que esta não se desloca, mas apenas gira sobre o seu próprio eixo horizontal ou vertical. 
panorâmica para o mesmo lado, seguindo os estudantes do fundo da sala que saem quando bate o sinal (Figura 8).

Figura 7 - Frame de Os Incompreendidos, François Truffaut, 1959

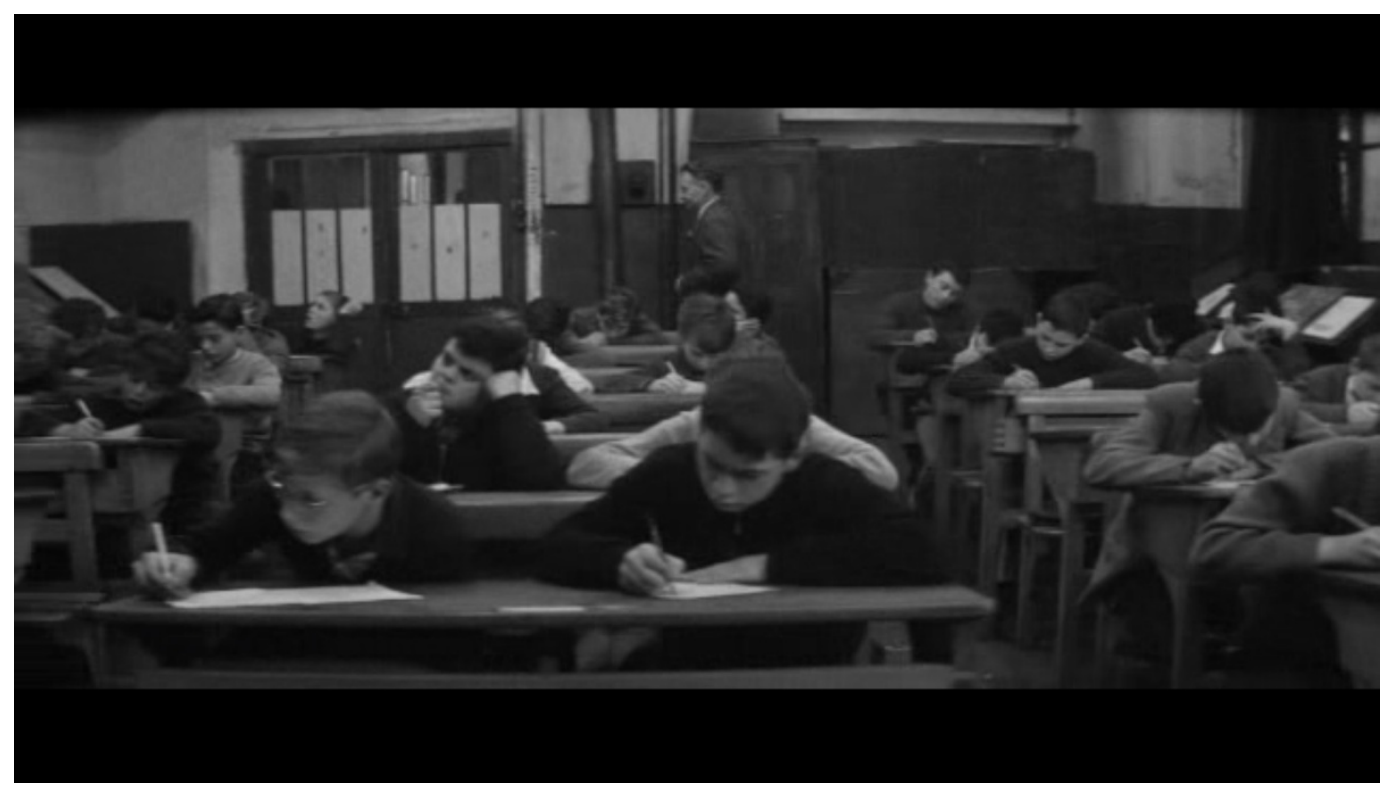

Fonte: Frame extraído de DVD original, acervo pessoal.

Figura 8 - Frame de Música e Preconceito, $8^{\circ}$ ano, EEEF Leopolda Barnewitz, 2014

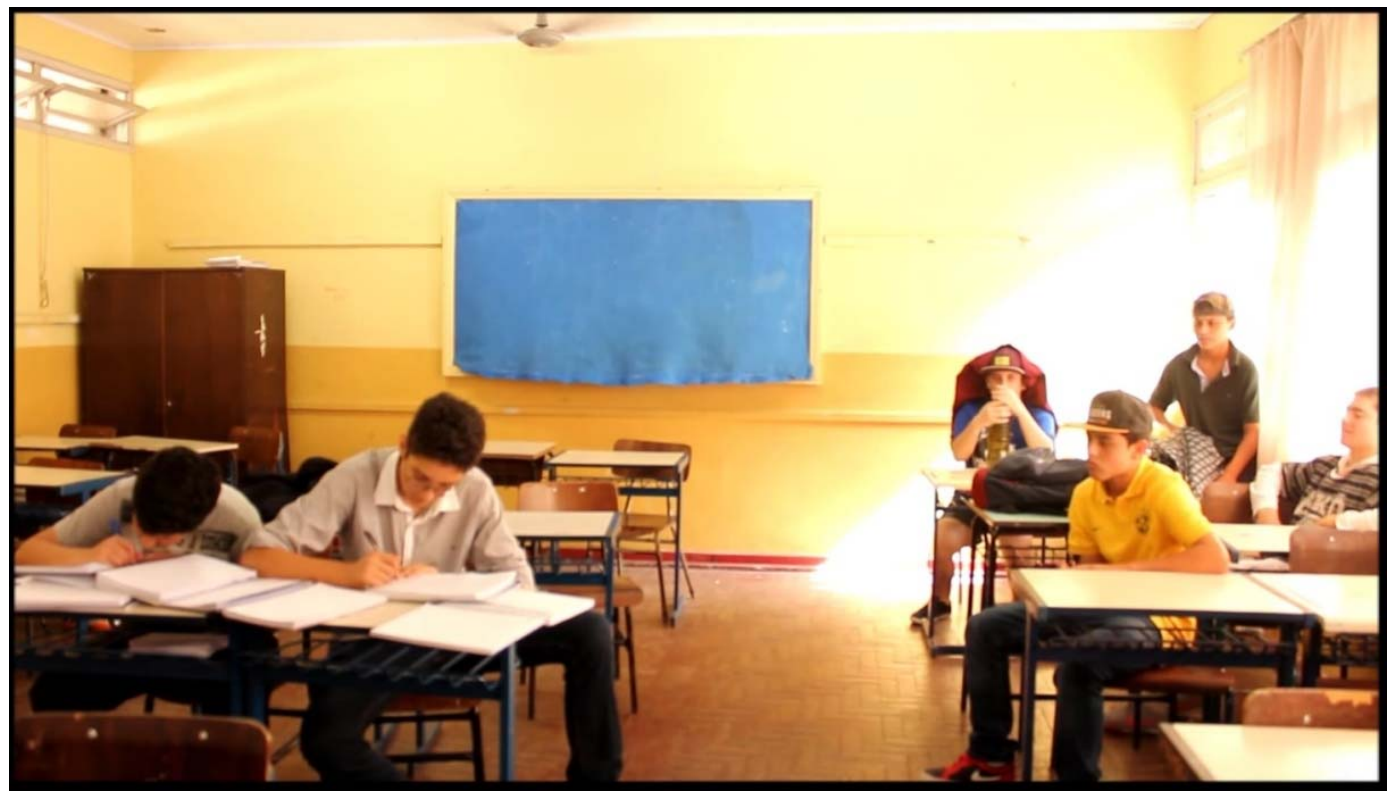

Fonte: Frame extraído do arquivo digital original do filme. 
Por fim, o último plano de Música e Preconceito (Figura 10) é um plano plongée ${ }^{11}$, semelhante ao plano-sequência ${ }^{12}$ inicial de Amarelo Manga (Figura 9), de Claudio Assis, trabalhado na proposição cinema brasileiro contemporâneo, com a diferença que no filme de Claudio Assis a câmera se movimenta pelo espaço e no filme dos alunos ela está parada.

Figura 9 - Frame de Amarelo Manga, Claudio Assis, 2002

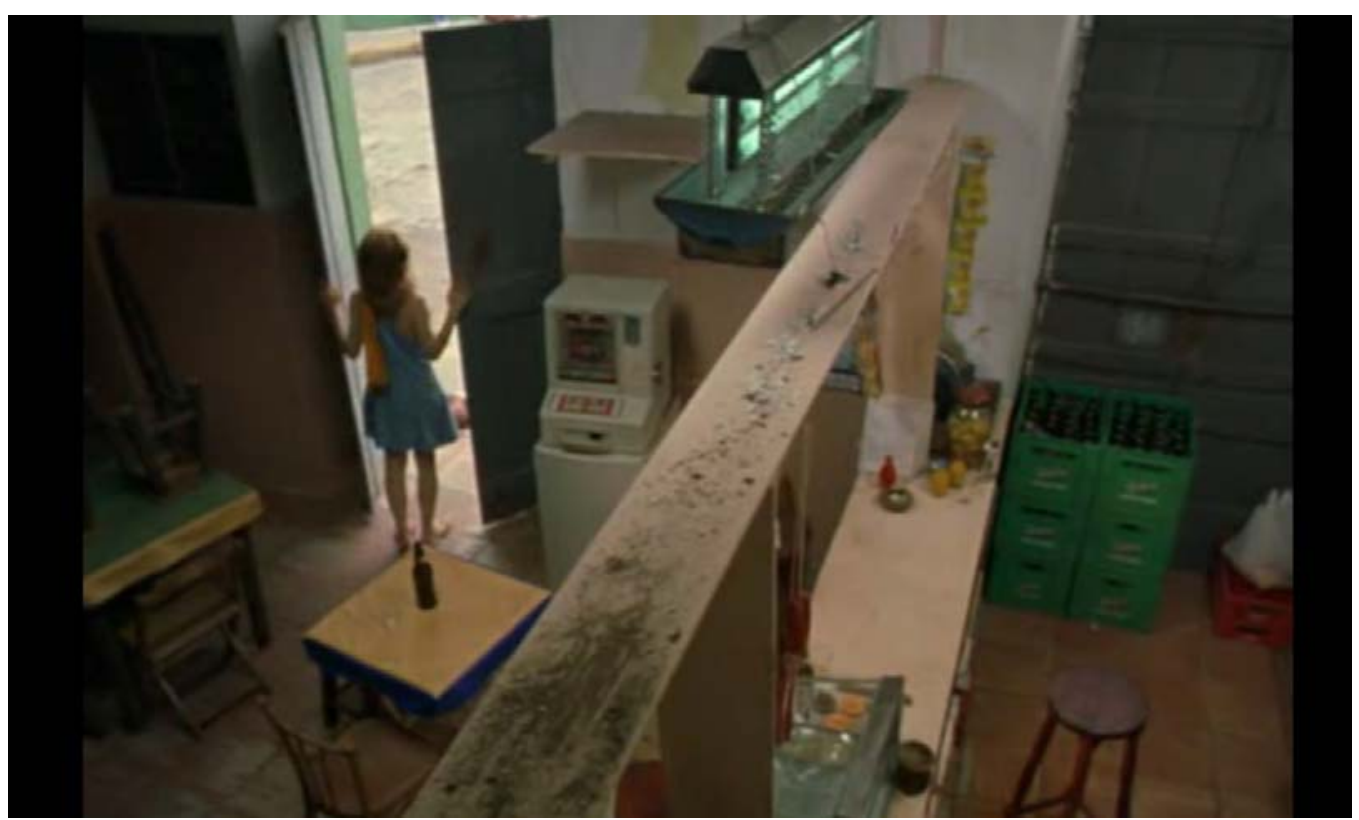

Fonte: Frame extraído de DVD original, acervo pessoal das autoras.

11 Plongée, que significa mergulhada em francês, é o termo usado para definir um tipo de enquadramento em que a câmera filma o objeto de cima para baixo. Fonte: $<$ http://paradadecinema.com.br/camera-em-plano-plongee-supercut>. Acesso em: 28 de setembro de 2015.

12 Plano-sequência, em cinema e audiovisual, é um plano que registra a ação de uma sequência inteira, sem cortes. Fonte: <https://pt.wikipedia.org/wiki/Plano-sequência>. Acesso em: 27 de setembro de 2015. 
Figura 10 - Frame de Música e Preconceito, $8^{\circ}$ ano, EEEF Leopolda Barnewitz, 2014

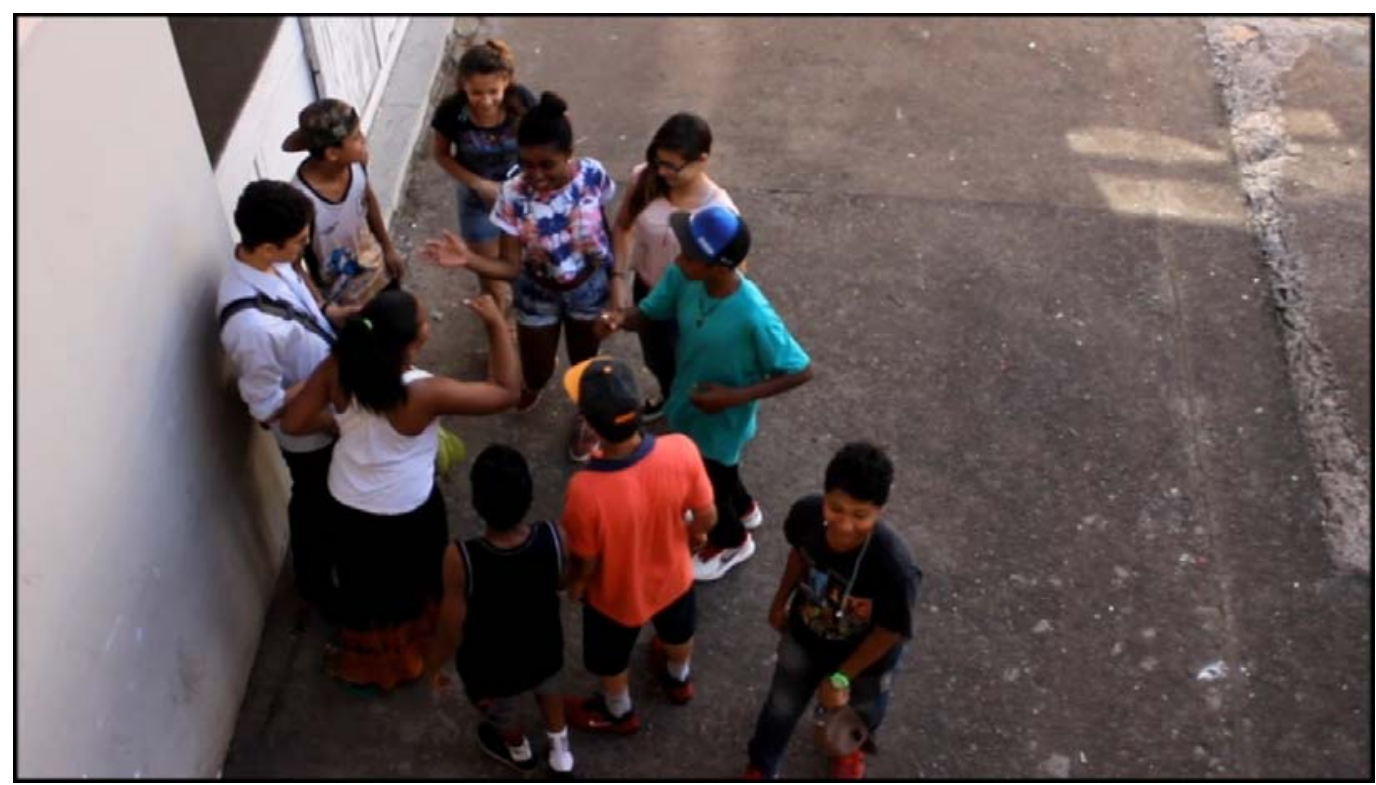

Fonte: Frame extraído do arquivo digital original do filme, acervo pessoal das autoras.

O curioso deste processo de apropriação é que em nenhum momento o diálogo entre imagens (filmadas pelos alunos e assistidas nas aulas de exibição) foi verbalizado, o que nos leva a crer que o repertório foi assimilado constituindo uma verdadeira memória das imagens, ampliando suas possibilidades de expressão nesta linguagem.

Foi possível observar também a vontade de diversificar as durações de planos, posições e movimentos de câmera e de que essas escolhas fossem sempre diferentes a cada cena. A impressão é de que os estudantes ansiavam por experimentar todas as possibilidades de expressão a que tinham sido apresentados durante o trabalho. Não há em Música e Preconceito dois planos similares em relação à forma. As situações de conflito e de resolução de conflito que o filme estabelece - um aluno novo que chega à escola e é recebido com hostilidade pelos colegas acaba sendo aceito pelo grupo por seu gosto musical - foram exploradas através de planos-sequência, planos-detalhe, close up, câmeras estáticas, em movimento, na mão e no tripé, em diferentes angulações, como um laboratório de experimentação da linguagem. 


\section{Compartilhando olhares}

Como ação de encerramento do projeto pedagógico, o grupo compareceu à IV Mostra Olhares da Escola, ação do Programa de Alfabetização Audiovisual. A Mostra Olhares da Escola exibe filmes escolares das redes públicas de ensino da cidade de Porto Alegre, realizados durante o ano letivo, em sessões comentadas por cineastas, educadores e críticos de cinema. Cada sessão exibe filmes de até três escolas, com a presença dos estudantes realizadores, que têm a oportunidade de verem seus filmes na tela grande do cinema, apresentar seus processos de trabalho e trocar experiência com seus pares. Na ocasião os alunos apresentaram o filme, tecendo comentários sobre o seu processo de realização, relatando o trabalho de sala de aula, os módulos de exibição, suas referências, assumindo a autoria do curta-metragem, enfim, construindo uma narrativa própria sobre a realização cinematográfica.

Todo o processo do trabalho na escola, de acesso a obras cinematográficas, produção e exibição de exercícios com imagens, dialoga com a concepção do Programa de Alfabetização Audiovisual, de abordagens múltiplas em relação aos diferentes caminhos que o cinema na sala de aula pode percorrer. Diferentemente de se criar um método para este trabalho, o PAA objetiva ser um espaço de compartilhamento e reflexão destas experiências, tornando-se uma referência e um apoio para os profissionais que queiram trabalhar esta linguagem em contexto escolar. Esse é também o objetivo do Vagalume, um laboratório de experimentações metodológicas que acolhe diferentes agentes a fim de trocar informações, formar parcerias e trocar ideias, enfim, compartilhar olhares; um espaço e um tempo para a ampliação das possibilidades e do alcance que a alfabetização audiovisual pode ter tanto na escola quanto em espaços informais de ensino, atuando na formação destes sujeitos (professores e alunos) para a apropriação da linguagem das imagens em movimento.

\section{Considerações finais}

Torna-se impossível definir o impacto que um projeto pedagógico como este tem sobre a constituição destes estudantes. Em primeiro lugar, pela 
impossibilidade de dimensionar a experiência vivida por cada sujeito e, segundo, pelo fato de que a experiência como processo atravessador do sujeito vai constituir o indivíduo e se manifestar como repertório por tempo indeterminado. Para Mário Alves Coutinho (2013, p.20), "sua eficiência (da arte) maior é pressupor e propor a liberdade de quem a experimenta, não impor. Cada qual aprende (se aprende) o que pode, o que dá conta." Ainda, segundo Fresquet (2013, p. 172): "para Godard, efetivamente o cinema não se ensina, porque o cinema não se aprende, como a literatura."

No entanto, é possível afirmar que o fio condutor para este tipo de projeto de alfabetização audiovisual, pensado sob a perspectiva da história das formas, deve começar na etapa de seleção dos filmes trabalhados, a fim de que estes falem por si mesmos, exigindo a mínima interferência do professor no contato obra cinematográfica/aluno. Ainda, que esses filmes assumam um contraponto em relação aos conteúdos de circulação majoritariamente comercial, como blockbusters, programas televisivos e conteúdo publicitário. Para Anita Leandro (2001, p. 34):

É didático o material audiovisual que ensina o espectador a resistir à estética dominante, construindo um pensamento crítico em relação ao próprio meio utilizado no processo educativo. [...] Pensar com imagens e sons é fazer do cinema ou do vídeo um ato de resistência.

Outra observação importante para o estudo do cinema a partir da história das formas é garantir o tempo de fruição dos filmes ou dos trechos de filmes. Em um tempo em que imagens em movimento de todos os tipos atravessam nosso cotidiano, com a velocidade da barra de rolamento do computador, permitir aos alunos ver, rever, ver mais uma vez, pausar, voltar, pensar e observar, estimula um diálogo com a imagem dificilmente alcançado em outro contexto que não o pedagógico. Diz Godard (apud Daney, 2007, p. 112) sobre a pedagogia do cinema:

Guardar um número de alunos para retardar o momento no qual eles se arriscariam a passar rápido demais de uma imagem à outra, de um som ao outro, ver rápido demais, pronunciar-se prematuramente, pensar em ter terminado com o cinema quando eles estão longe de suspeitar a que ponto o agenciamento dessas imagens e desses sons é coisa complexa, grave, sem inocência. 
Perguntar e responder com imagens é um processo de médio e longo prazo. Se "a imagem pensa" como afirma Godard no filme História(s) do Cinema, estabelecer processos que resultem em uma abertura sensível e cognitiva para esta racionalidade é tarefa árdua e de risco. Segundo Daney (2007), a dialética da "pedagogia godardiana", consiste em assumir o que é dito, não questionando jamais a legitimidade do enunciado ou do enunciador, mas procurar sempre o "outro" enunciado, o outro som, a outra imagem que poderia vir a se contrabalancear, travar relação, constituindo assim o espaço vazio no qual as imagens e sons coexistem, se reconhecem, se nomeiam e se embatem.

Seria mais racional falarmos em possibilidades de alfabetizações audiovisuais, inúmeros são os processos, levando em consideração os contextos e os sujeitos envolvidos. Adriana Fresquet (2013, p. 17) lembra Brecht ao dizer que não podemos esquecer o imperativo "apague as pegadas", para que os que venham atrás tenham a chance de criar seus próprios caminhos. $O$ cinema, como diz Paulo Henrique Vaz (2013, p. 55), não é o lugar ou o meio ideal para o ensino de nada, a função da arte é levantar dúvidas e promover questionamentos.

\section{Referências}

AUMONT, Jaques. Pode um filme ser um ato de teoria? Educação \& Realidade: Cinema e Educação, v. 33, n.1, p. 21-34, 2008.

BARBOSA, Maria Carmen Silveira; SANTOS, Maria Angélica. (Org.). Escritos de Alfabetização Audiovisual. Porto Alegre: Libretos, 2014.

BERGALA, Alain. La hipótesis del Cine: pequeno tratado sobre la transmisión del cine en la escuela y fuera de ella. Barcelona: Laertes Educación, 2007.

COUTINHO, Mário Alves. Introdução II: Jean-Luc Godard ou a pedagogia do Não. In: COUTINHO, Mário Alves; MAYOR, Ana Lucia Soutto. (Orgs.). Godard e a educação. Belo Horizonte: Autêntica, 2013. p. 19-25.

DANEY, Serge. O therrorisado. Pedagogia Godardiana. A rampa: cahiers du cinema 1970-1982. São Paulo: Cosac Naify, 2007.

FRESQUET, Adriana. Infância por infância. In: COUTINHO, Mário Alves; MAYOR, Ana Lucia Soutto. (Orgs.). Godard e a educação. Belo Horizonte: Autêntica, 2013. p. 169-181.

LEANDRO, Anita. Da imagem pedagógica à pedagogia da imagem. Comunicação \& Educação, v. 7, n. 21, p. 29-36, 2001.

OLIVEIRA JR. Luiz Carlos. A mise en scène no cinema: do clássico ao cinema de fluxo. Campinas: Papirus, 2013.

OLIVEIRA JR. Luiz Carlos. Vertigo, a teoria artística de Alfred Hitchcock e seus desdobramentos no cinema moderno. Tese (Doutorado) - Departamento de Cinema, Rádio e Televisão/Escola de Comunicação e Artes/USP. São Paulo, 2015. 
PEREIRA, Marcos Villela. Contribuições para entender a experiência estética. Revista Lusófona de Educação, v. 18, p. 111-124, 2011.

SILVA, Maria Cristina Miranda da. A reinvenção do(s) cinema(s) na formação do espectador contemporâneo: pedagogia godardiana. In: COUTINHO, Mário Alves; MAYOR, Ana Lucia Soutto. (Orgs.). Godard e a educação. Belo Horizonte: Autêntica, 2013. p. 139-155.

SILVA, Edson Rosa da. O museu imaginário e a difusão da cultura. Semear: Revista eletrônica da Cátedra Padre Antônio Vieira de Estudos Portugueses, n. 6, s/p, 2002. Disponível em: http://www.letras.puc-rio.br/unidades\&nucleos/catedra/index.html

TEIXEIRA, Inês Assunção et al. (Orgs.) A infância vai ao cinema. $2^{\mathrm{a}}$ ed. Belo Horizonte: Autêntica, 2014.

VASCONCELLOS, Jorge. A Pedagogia da Imagem: Deleuze, Godard: ou como produzir um pensamento do cinema. Educação \& Realidade: Cinema e Educação - v. 33. n. 1. Porto Alegre: Editora da UFRGS, 2008.

VASCONCELLOS, Jorge. (Org.) A experiência do cinema: antologia. Rio de Janeiro: Edições Graal, 1983.

VAZ. Paulo Henrique. Prenome Jean-Luc: notas sobre as possibilidades de uma pedagogia sem garantias. In: COUTINHO, Mário Alves; MAYOR, Ana Lucia Soutto. (Orgs.). Godard e a educação. Belo Horizonte: Autêntica, 2013. p. 39-49.

\section{Referências fílmicas}

A Esquiva. Direção: Abdellatif Kechiche. França: Lola Filmes e Noé Production, 2003 [produção]. 117 min., cor. DVD acervo pessoal.

Amarelo Manga. Direção: Claudio Assis. Recife: Olhos de Cão Produtora, 2002 [produção]. 101 min., cor. DVD acervo pessoal.

Chegada de um trem à estação; Saída da fábrica; Refeição de um bebê; Demolição de um muro; O jardineiro regado; Jogo de cartas; Partindo de Jerusalém pela estrada de ferro e Engate de um caminhão. Irmãos Lumière. Paris: Cinématographe Lumière, 1985 e 1986.7 min., p\&b. DVD Material didático Inventar com a Diferença.

Elephant. Direção: Gus Van Sant. EUA: Estúdio HBO, 2003 [lançamento mundial]. 81 min., cor. DVD acervo pessoal.

Febre do Rato. Direção: Claudio Assis. Recife: República Pureza Filmes e BelaVista Cinema, 2011[produção]. 110 min., cor. DVD acervo pessoal.

História(s) do Cinema. Direção: Jean Luc-Godard. França: 1988 [lançamento mundial]. 266 min., cor. DVD acervo pessoal.

Hoje Eu Quero Voltar Sozinho. Direção: Daniel Ribeiro. São Paulo: Lacuna Filmes, 2014 [produção]. 96 min., DVD acervo pessoal.

O Som ao Redor. Direção: Kleber Mendonça. Recife: CinemaScópio, 2012 [produção]. 131 min., cor. DVD acervo pessoal.

Onde Fica a Casa do Meu Amigo. Direção: Abbas Kiarostami. Irã: 1983 [estreia mundial]. 83 min., cor. DVD acervo pessoal.

Os Incompreendidos. Direção: François Truffaut. França: 1959 [estreia mundial]. 99 min., p\&b. DVD acervo pessoal.

Os Indigentes do Bom Deus. Direção: Jean Claude Brisseau. França: 2000 [lançamento mundial]. 107 min., cor. DVD acervo pessoal. 


\section{Juliana Costa}

Graduada em Licenciatura em Artes Visuais pela Universidade Federal do Rio Grande do Sul (2014), é mestranda da linha de pesquisa Estudos sobre as Infâncias, sob orientação da Profa. Dra. Maria Carmen Silveira Barbosa, tendo sua pesquisa voltada para as intersecções entre cinema e educação, cinema e infância, cinema e sala de aula. Atuou de 2012 a 2015 como bolsista do Programa de Alfabetização Audiovisual.

E-mail: juvieiracosta01@gmail.com

Currículo: http://buscatextual.cnpq.br/buscatextual/visualizacv.do?id=K8243402P9

\section{Maria Carmen Silveira Barbosa}

Graduada em Pedagogia pela Universidade Federal do Rio Grande do Sul (1983), especialista em Alfabetização em Classes Populares pelo GEEMPA (1984) e em Problemas no Desenvolvimento Infantil pelo Centro Lidia Coriat (1995), mestre em Planejamento em Educação pela Universidade Federal do Rio Grande do Sul (1987), Doutora em Educação pela Universidade Estadual de Campinas (2000) e Pós-doutora pela Universitat de Vic, Catalunya, Espanha (2013). Atualmente é Professora Associada da Faculdade de Educação da Universidade Federal do Rio Grande do Sul e atua no Programa de Pós-Graduação em Educação, na Linha de Pesquisa: Estudos sobre as Infâncias. Atua como coordenadora do projeto de extensão da UFRGS Programa de Alfabetização Audiovisual, desde 2011.

E-mail: licabarbosa@ufrgs.br

Currículo: http://buscatextual.cnpq.br/buscatextual/visualizacv.do?id=K4767952P9 